\title{
Effect of Thrombocytopenia on Age and Method of Delivery among Pregnant Women in Late Trimester
}

\author{
SHAZIA AWAN ${ }^{1}$, SHAZIA RANI ${ }^{3}$, SAIRA DARS ${ }^{3}$, MADIHA ABBASSI $^{4}$, NAHEED PARVEEN ${ }^{5}$, RAHEEL SIKANDAR ${ }^{6}$ \\ ${ }^{1,3}$ Assistant Professors, ${ }^{2,5}$ Associate Professors, ${ }^{4}$ Senior Registrar, ${ }^{6}$ Professor, \\ Department of Obstetrics \& Gynaecology, Liaquat University of Medical \& Health Sciences Jamshoro \\ Correspondence to Dr. Shazia Awan E-mail: shaziaasad38@gmail.com Cell: 0333-53655867
}

\begin{abstract}
Aim: To evaluate the effect of thrombocytopenia in pregnant women.

Study design: Descriptive cross-sectional hospital based study

Place and duration of study: Department of Obstetrics \& Gynaecology, Liaquat University of Medical and Health Science Jamshoro from $1^{\text {st }}$ June 2018 to $31^{\text {st }}$ June 2019.

Methodology: One hundred and seventy-six patients were observed. Women with pre-eclampsia, platelets less than $50 \times 10^{10}$, singleton pregnancy and pregnancy greater than 32 weeks were included.

Results: Most of the participants $91(51.9 \%)$ were 26 to 30 years with mean age was $30.71 \pm 4.45$ years. Gestational duration in last trimester was $50(28.4 \%), 98(55.7 \%)$ and $28(15.9 \%)$ of 28 to 32 Weeks, 32 to 36 Weeks and greater than 36 weeks respectively. Mean gestational duration was $35.11 \pm 2.3$ Weeks. Seventy-one were falling in range of platelets of $30 \times 10^{10}$ to $40 \times 10^{10}(40.3 \%)$. Others were $46(26.1 \%)$ of $>40 \times 1010,43(24.4 \%)$ of $20 \times 10-30 \times 10^{10}$ and $16(9.1 \%)$ of $10 \times 10-20 \times 10^{10}$. One hundred and $41(80.1 \%)$ had vaginal deliveries and $35(19.9 \%)$ had lower segment caesarean section deliveries.
\end{abstract}

Conclusion: The young participants of thrombocytopenia were more prevalent than old age participants.

Keywords: Gestational thrombocytopenia, Platelet count, Pregnancy

\section{INTRODUCTION}

In pregnant ladies, there may be $7 \%-11 \%$ got thrombocytopenia in all age groups ${ }^{1}$. Regarding types, gestational thrombocytopenia is more prevalent than other types. With other mild to severe complications like High blood pressure, Gestational diabetes, Infections, Miscarriage and still birth²; thrombocytopenia occurs as hematologic complication in pregnant women at any stage of pregnancy. Thrombocytopenia arises during and after pregnancy, that is a condition in which an individual have abnormal level of platelets $^{3}$. There are different classifications used for abnormal levels of thrombocytopenia. One classification is mild, moderate and severe loss of platelets. Respective numbers classified for mild, moderate and severe are $100-150 \times 10^{9} / \mathrm{L}, 50-100 \times 10^{9} / \mathrm{L}$ and $50 \times 10^{9} /$ L. $^{4}$

There are different causes for this reduction of platelets count ${ }^{5}$, about $10 \%$ of pregnant ladies could be affected by thrombocytopenia. ${ }^{6}$ As levels of platelets are classified, in same way types of thrombocytopenia are also classified in many different ways. Major types include, pregnancy-associated thrombocytopenia (PAT)/gestational thrombocytopenia which is about $65 \%$ or more ${ }^{7}$, idiopathic thrombocytopenia/immune thrombocytopenia (ITP) and hypertensive disorder in pregnancy $(\mathrm{PIH})$.

Regarding pregnancy-associated thrombocytopenia/ Gestational thrombocytopenia, cause of this type is not yet clear. But it is assumed that it may occur because of hemodilution in pregnant cases and within placenta annihilation of thrombocytes ${ }^{8,9}$. Pregnancy-associated thrombocytopenia falls in category when number of platelets must be better than $70 \times 109 / L^{10}$. Usually PAT

Received on 17-12-2020

Accepted on 29-04-2021 doesn't occur at initial stage of pregnancy but at late stage frequently in third trimester it happens. It is good to know that with care and consideration within 12 weeks of delivery number of platelets comes to normal level in blood ${ }^{11-13}$. In PAT, it is possible that an insignificant hemorrhage may occur to mother but in many cases PAT is measured as insignificant type of thrombocytopenia in prenatal ladies.

In some cases, auto-antibodies platelets come out in immune thrombocytopenia ITP, those auto-antibodies with platelets destruct platelets membrane which reduces clotting of blood, in result thrombocytes reduced very quickly. ${ }^{14}$ As compare to PAT, ITP need more care and consideration in prenatal as well as in postnatal stage because of severe reduction in number of platelets which consequently increases risk of maternal hemorrhage. On other hand ITP cases are not more than $5 \%$ rather that $\mathrm{PAT}$, it is categorized by a modest to severe reduction in the platelet count. ${ }^{15,16}$

Generally neonatal babies are at very low risk of decreased platelets count. After delivery of child, mother with thrombocytopenia may gain enough platelets count in less than one week. ${ }^{17}$ While some causes of thrombocytopenia, such as incidental thrombocytopenia of pregnancy, have no impact on pregnancy outcomes than others. ${ }^{18}$ In late stage of thrombocytopenia risk of postpartum hemorrhaging, neonatal asphyxia and other conditions rise in pregnancy ${ }^{9}$.

In antenatal and postnatal cases of thrombocytopenia, uses of medicines are usually to maintain harmless level of platelet count. Treatment generally contains steroids and intravenous immunoglobulin ${ }^{19}$.

The aim of this study is to evaluate effect of thrombocytopenia on pregnant women. This study will help to decide which age group is more prevalent among thrombocytopenic pregnant women, how much late 
thrombocytopenia occurs in third trimester and which method of delivery is prevalent in among thrombocytopenic pregnant women.

\section{MATERIALS AND METHODS}

This was a descriptive retrospective cross-sectional study of antenatal and postnatal women with thrombocytopenia attended Department of Obstetrics \& Gynaecology Liaquat University of Medical \& Health Sciences Jamshoro from $1^{\text {st }}$ June 2018 to $31^{\text {st }}$ June 2019. All pregnant women were admitted to labor ward with thrombocytopenia with platelet count less than $50 \times 10^{10}$. Women with pre-eclampsia, platelets less than $50 \times 10^{10}$, singleton pregnancy and pregnancy greater than 32 week were included. Ladies with multiple pregnancy, gestational diabetic mellitus, chronic hypertension and $\mathrm{K} / \mathrm{C}$ of autoimmune thrombocytopenia (ITP) were not included study due multiple factors. Data was entered and analyzed in SPSS 20.

\section{RESULTS}

Ninety-one (51.9\%) women belonged to $26-30$ years, $39(22.2 \%)$ of $31-35$ years, $26(14.8 \%)$ of $21-25$ years, $16(9.1 \%)$ of $36-40$ years and $4(2.3 \%)$ of $41-45$ with mean age was $30.71 \pm 4.45$ years.

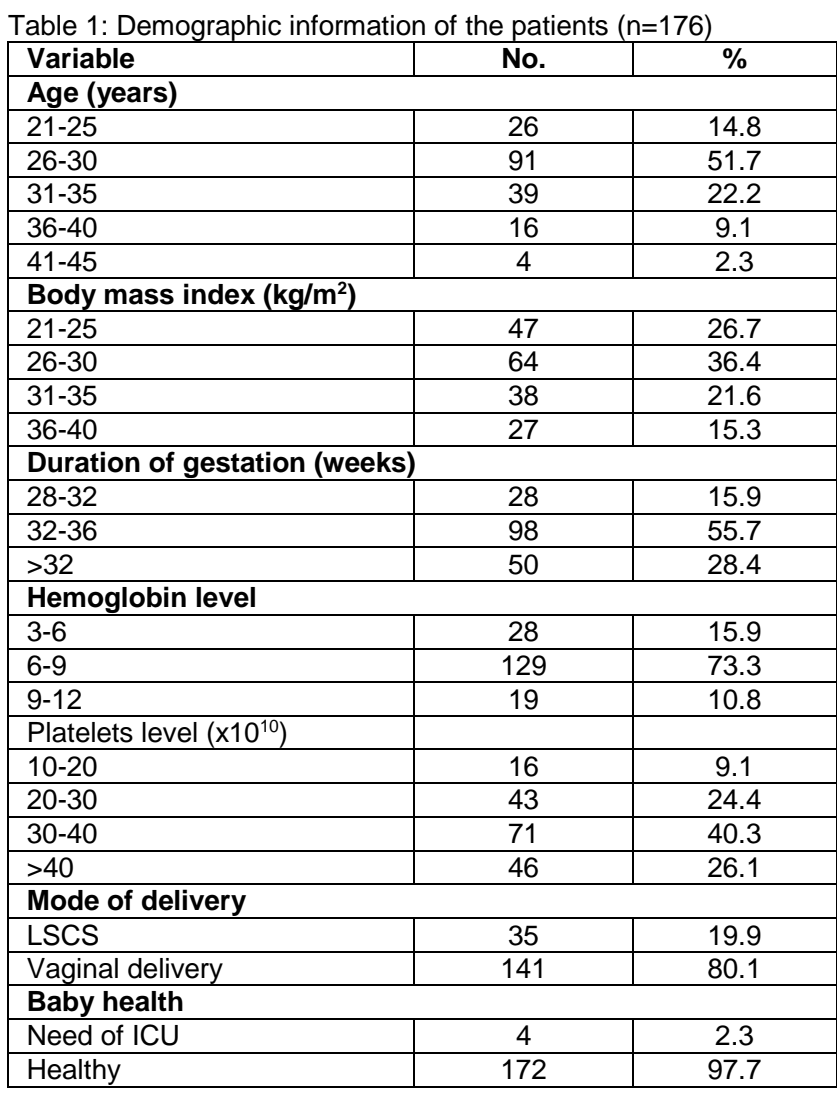

The level of BMI among 21-25 were in 47(26.7\%), 26-30 in $64(36.4 \%), 31-35$ in $38(21.6 \%)$ and $36-40$ in $27(15.3 \%)$ with mean BMI was 29.68 \pm 5.1 . Gestational duration in their last trimester were 50(28.4\%), 98 (55.7\%) and 28(15.9\%) of 28 to 32 weeks, 32 to 36 weeks and greater than 36 weeks respectively. Mean gestational duration were $35.11 \pm 2.3$ weeks. Seventy-one (40.3\%) women were falling in range of $30 \times 10^{10}$ to $40 \times 10^{10}$ platelets count. Other levels of platelets were $46(26.1 \%)$ of $>40 \times 10^{10}, 43(24.4 \%)$ of $20 \times 10-30 \times 10^{10}$ and $16(9.1 \%)$ of $10 \times 10-20 \times 10^{10}$.

The hemoglobin level was 3-6 among 28 (15.9\%) participants, $6-9$ in $129(73.3 \%)$ and $9-12$ in $19(10.8 \%)$ participants. Most of the participants $141(80.1 \%)$ were handled with vaginal delivery method and rest of participants 35(19.9\%) needed lower segment caesarean section (Table 1).

\section{DISCUSSION}

We have tried to figure out, in what age group it is more prevalent, in which gestational age thrombocytopenia is more than in other and which level is more usual of platelets in thrombocytopenia. We observed that it is more prevalent in 26 to 30 years of age group than other age groups.

Mainly pregnant participates, more than half of total, observed thrombocytopenia occurs in between 32 to 36 weeks of pregnancy which is late trimester of pregnancy. This resembles with study conducted by Crowther et al ${ }^{20}$ who described that gestational thrombocytopenia in pregnancy is a condition that advances mostly in the late second or third trimester. Another study conducted at Nigeria showed that gestational thrombocytopenia progresses from first to third trimester consistently. ${ }^{21} \mathrm{~A}$ study conducted at late trimester of pregnancy by Sainio ${ }^{22}$ showed more pregnant women become thrombocytopenic at late stage of pregnancy.

We observed $40.3 \%$ participants had mild platelets count, $30-40 \times 10^{10}$. This agrees with the outcome of Boehlen $^{23}$, who stated that gestational thromcytopenia is frequently mild. Calderwood ${ }^{24}$ suggested that generally most of the women with thrombocytopenia remain asymptomatic because of pro-coagulent state which is getting better with levels of fibrinogen, and inhibited fibrinolysis. Ajibola et $\mathrm{al}^{21}$ reported that maximum of the cases of thrombocytopenia (78.4\%) were mild with platelet counts above $100 \times 10^{9} / \mathrm{L}$. Myers ${ }^{25}$ reported that maximum cases of thrombocytopenia in pregnancy are mild, with no adverse consequence for mother or baby, occasionally a low platelet count may be part of a composite disorder with greater morbidity and may (seldom) be life-threatening.

In the present study, $80.1 \%$ has been delivered babies with vaginal delivery method. Myers ${ }^{25}$ reported that mode of delivery must be established on obstetric considerations assumed there is no evidence that caesarean section is harmless for the foetus with thrombocytopenia than an uncomplicated vaginal delivery, which is typically safer than caesarean section for the mother. Ciobanu ${ }^{26}$ suggested that vaginal delivery is safe when platelet count is higher than $30.000 / \mathrm{iL}$ for operative vaginal or caesarean deliveries, the safe platelet count should be $50.000 / \mathrm{iL}$.

\section{CONCLUSION}

The young participants of thrombocytopenia were more prevalent than old age participants. The women with thrombocytopenia did not required lower segment 
caesarean section procedure, most of the participants delivered babies with vaginal delivery method and most of the babies were not required intensive care.

\section{REFERENCES}

1. Franchini M, Veneri D, Lippi G. Thrombocytopenia and infections. Expert Rev Hematol 2017;10(1):99-106.

2. What are some common complications of pregnancy? [Internet]. Eunice Kennedy Shriver National Institute of Child Health and Human Development. National Institutes of Health, 2020

3. Lee EJ, Lee Al. Thrombocytopenia. Prim Care 2016;43(4):543-57.

4. Yamashita E, Okada H, Yorioka H, Fujita S, Nishi K, Komiyama $Y$, et al. Successful management of pregnancyassociated thrombotic thrombocytopenic purpura by monitoring ADAMTS13 activity. J Obstet Gynaecol Res 2012; 38(3):567-9.

5. Smock KJ, Perkins SL. Thrombocytopenia: an update. Int J Lab Hematol 2014;36(3):269-78.

6. Fogerty $A E$. Thrombocytopenia in pregnancy: mechanisms and management. Transfus Med Rev 2018;32(4):225-9.

7. Gernsheimer TB. Thrombocytopenia in pregnancy: Is this immune thrombocytopenia or...? Hematology Am Soc Hematol Educ Program 2012;2012:198-202.

8. Webert KE, Mittal R, Siguoin C, Heddle Nm, Kelton JG. A retrospective 11-year analysis of obstetric patients with idiopathic thromobocytopenic purpura. Blood 2003;102: 430611.

9. Kelton JG. Idiopathic thrombocytopenic purpura complicating pregnancy. Blood Rev 2002; 6:43-6.

10. Wang $X, X u Y$, , Luo $W$, Feng $H$, Luo $Y$, Wang $Y$, Liao $H$. Thrombocytopenia in pregnancy with different diagnoses: Differential clinical features, treatments, and outcomes. Medicine (Baltimore) 2017;96(29):e7561.

11. Chitra TV, Panicker S. Maternal fetal outcome of dengue fever in pregnancy J Vector Borne Dis 2011; 48(4):210-3.

12. Tanimura K, Ebina $\mathrm{Y}$, Sonoyama A, Morita H, Miyata S, Yamada $H$. Argatroban therapy for heparin-induced thrombocytopenia during pregnancy in a woman with hereditary antithrombin deficiency. J Obstet Gynaecol Res 2012; 38(4):749-52.
13. Chen Z, Liang My, Wang JI, Zhonghua FU, Chan KE, Za Zhi. Etiology and clinical characteristics of pregnancy-emerged thrombocytopenia $2011 ; 46(11): 834-9$.

14. Nomura RM, Igai AM, Costa VN, Miyadahira S, Zugaib M. Assessment of fetal well-being In pregnancies complicated by maternal moderate to severe thrombocytopenia. Rev Bras Gynecol Obstet 2011; 33(10):280-5.

15. Shehata N, Burrows RF, Kelton JG. Gestational thrombocytopenia. Clin Obstet Gynecol 1999; 42:327-34.

16. Provan D, Stasi R, Newland AC. International Consensus Report on the investigation and management of primary immune thrombocytopenia. Blood 2010;115:168-86.

17. Burrows RF, Kelton JG. Incidentally Detected Thrombocytopenia in healthy mothers and their Infants. $\mathrm{N}$ Engl J Med 2006; 319:142-5.

18. Michelson A, Cattaneo M, Frelinger A. Platelets. $4^{\text {th }}$ ed. Academic Press, 795-812.

19. Gill KK, Kelton JG. Management of idiopathic thrombocytopenic purpura in pregnancy. Sem Hematol 2000;37:275-83.

20. Crowther MA, Burrows RF, Ginsberg J, Kelton JG. Thrombocytopenia in pregnancy: diagnosis, pathogenesis and management. Blood Rev 1996;10:8-16.

21. Ajibola SO, Akinbami A, Rabiu K, Adewunmi A, Dosunmu A, Adewumi $A$, et al. Gestational thrombocytopaenia among pregnant women in Lagos, Nigeria. Niger Med $J$ 2014;55(2):139-43.

22. Sainio S, Kekomäki R, Riikonon S, Teramo K. Maternal thrombocytopenia at term: a population-based study. Acta Obstet Gynecol Scand 2000; 79(9):744-9.

23. Boehlen F, Hohlfeld P, Extermann P, Perneger TV, de Moerloose P. Platelet count at term pregnancy: a reappraisal of the threshold. Obstet Gynecol 2000;95:29-33.

24. Calderwood C. Thromboembolism and thrombophilia in pregnancy. Curr Obstet Gynaecol 2006; 16: 321-6.

25. Myers B. Diagnosis and management of maternal thrombocytopenia in pregnancy. $\mathrm{Br} \mathrm{J}$ Haematol 2012; 58: 315.

26. Ciobanu AM, Colibaba S, Cimpoca B, Peltecu G, Panaitescu AM. Thrombocytopenia in pregnancy. Maedica (Buchar) 2016;11(1):55-60. 